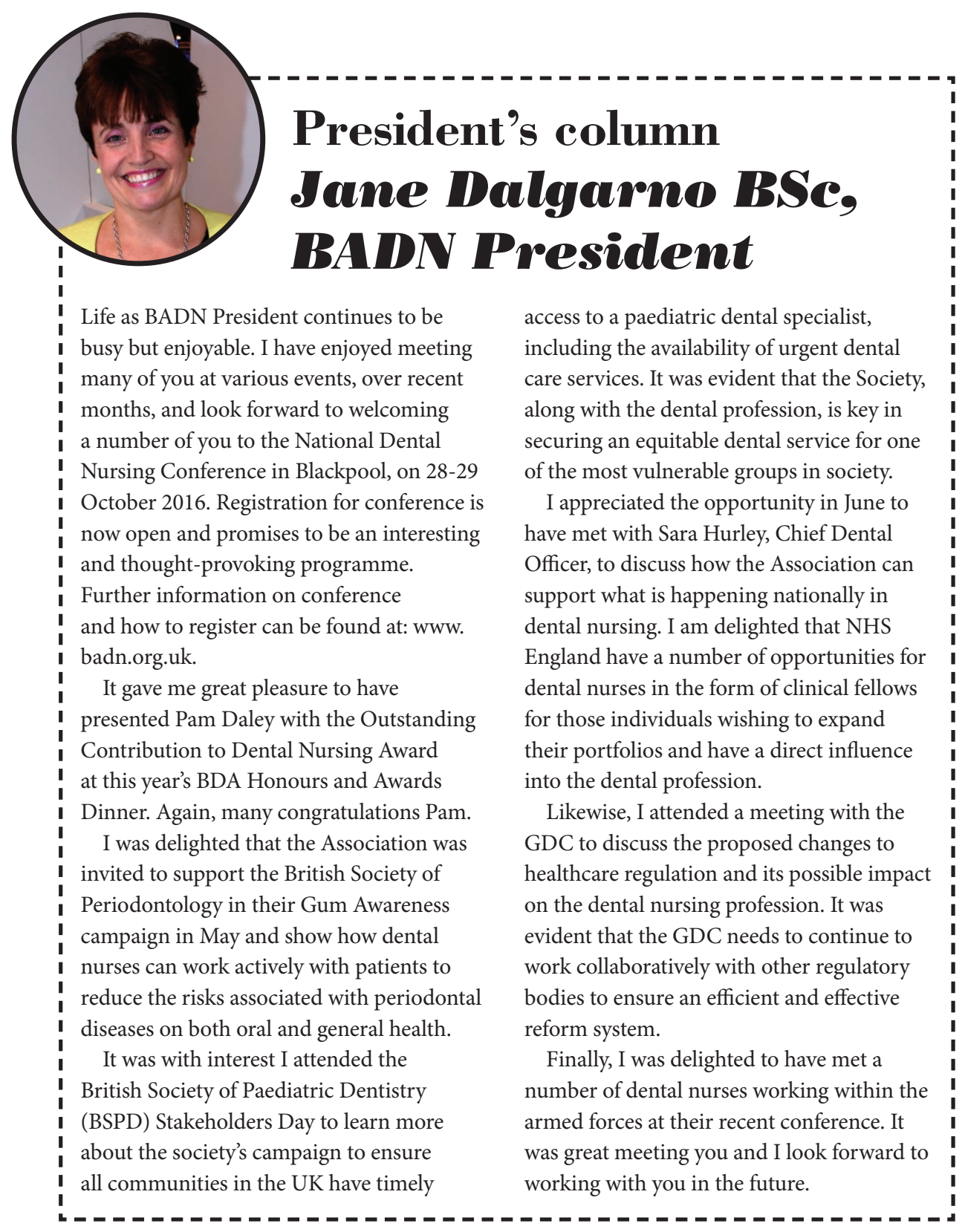

\section{Do you have appropriate indemnity?}

As the deadline for dental care professionals (DCPs) to renew their registration with the General Dental Council (GDC) approached at the end of July, the Dental Defence Union (DDU) reminded DCPs that it is their responsibility to ensure they have access to indemnity in their own right or that appropriate arrangements are in place via their employer.

Following a legal change, the GDC changed its rules in November 2015, meaning all dental professionals applying to register or renew their registration will need to tell the GDC they have indemnity arrangements in place for their scope of practice, or will have by the time they start practising.

John Makin, Head of the DDU, said: 'We have received a number of queries, particularly from dental nurses, about whether the indemnity they have in place meets the GDC's new requirements. Our advice is to check with your employer if you are not sure about what indemnity arrangements you have in place in the first instance'.

The GDC has published some Frequently Asked Questions about indemnity at http:// www.gdc-uk.org/dentalprofessionals/ standards/pages/indemnity.aspx.

\title{
End of NHS bursary undermines the dental team
}

The British Dental Association (BDA) has criticised government plans to strip dental hygiene and dental therapy students of the NHS bursary.

Many student dental therapists, hygienists, nurses, midwives and other Allied Health Professionals are funded through the scheme, which includes support towards living costs and students' tuition fees. Full time students also qualify for a $£ 1,000$ non means tested maintenance grant. This funding system is set to be replaced by full student loans from September 2017.

The BDA has said the move would significantly increase debt levels, and deter students from less privileged backgrounds or those undertaking second degrees. It has also cautioned that the reforms could put many dental hygiene and therapy course providers under threat of closure, and would not allow for sufficient workforce planning threatening the delivery of the NHS Five Year Forward View.

The changes proposed by the Government for 2017-18 would leave the average student with a maintenance loan of $£ 7,263$ and a tuition fee loan of $£ 9,000$ - with the BDA estimating a likely increase of over $£ 11,000$ in average costs to each student per academic year. Research has estimated that any savings generated by axing the bursary would be more than wiped out by an increase in spending on agency staff and overseas recruitment costs.

The BDA recently joined with leaders from 19 other health care trade unions, charities and professional colleges to call on the Government to halt the plans to reform student funding. At present over 2,500 dental

\section{ther-}

apists

and

over 6,500

hygienists are

registered with the

General Dental Council. It

is widely anticipated

these reforms will be

extended to student

medics and dentists.

Paul Blaylock, Chair of the BDA's Students

Committee, said: 'Dental hygienists and therapists are instrumental in delivering treatment, prevention and healthcare education to patients. The Government says prevention and public health require a "radical upgrade", yet this cut is an entirely retrograde step, that would deliver no savings and simply serve to undermine dental teams.' 